\title{
Investigation of the Dynamic Characteristics and Machining Stability of a Bi-rotary Milling Tool
}

\author{
Jui-Pin Hung ${ }^{1 *}$, Wei-Zhu Lin ${ }^{1,2}$ \\ 1 Graduate Institute of Precision Manufacturing, National Chin-Yi University of Technology, Taichung 41170, \\ Taiwan \\ 2 Intelligent Machine Tool Technology Center, Industry Technology Research Institute, Central Region Campus, \\ Taichung 54041, Taiwan \\ * Corresponding author e-mail: hungjp@ncut.edu.tw
}

\begin{abstract}
Bi-rotary milling head is the primary component of multiple-axis machine tool toward the multiply machining operation. The machining performance is greatly related to the structure characteristics and positioning precisions of the swivel head. This study was aimed at developing a bi-rotary milling head module, which is composed of a direct drive motor, cross roller bearings and motorized spindle unit. In order to evaluate the machining stability at the design phase, the dynamic characteristics of the rotary milling were first analyzed with finite element method. Especially, the variations of the dynamic characteristics of the spindle tool with the changing of the titling configuration of swivel axis were examined. In order to consider the accurate presentation of a spindle tool system and swivel mechanism, the bearings in the rolling components were also included in the finite element model and simulated with surface contact elements with adequate contact stiffness. The dynamic frequency response function of the spindle tool at different swinging positions were predicted for comparisons, which were further used to calculate the machining stability based on the machining mechanics. The current results show that the feeding direction and swinging positions of rotary milling head have a significant influence on the dynamic characteristics and machining ability of the spindle tool. The variations of the cutting depth with the swinging of A axis fall in the range of $11 \%$ to $40 \%$, depending on the feeding direction and swinging angle. The analysis results are expected to clearly demonstrate the variation of the machining performance of the spindle tool under different milling configurations. The devised model and modeling approach can be applied to develop a five axis milling machine with desired dynamic and machining performance.
\end{abstract}

Keywords: bi-rotary milling head, dynamic characteristics, five-axis milling machine, machining stability

\section{INTRODUCTION}

Bi-rotary milling head is the primary component of multiple-axis machine tool toward the multi-function in various industries such as aerospace, energy production, electronic and medical. The machining performance of spindle tool is greatly dependent on the dynamic characteristics of the machine frame and the rotary milling head, since it directly affects the positioning precisions and machining stability. Considering the demand for dynamic performance in high speed feeding, currently most of the rotary milling head are driven by torque motors in $\mathrm{A}$ and $\mathrm{C}$ axes be- cause of the advantages such as compact structure, no transmission backlash and high positioning precision.

For a five-axis milling with bi-rotary spindle head, the tool orientations are controlled to change with the changing tool path. The spindle tool is generally normal to the part surface, thus yielding a tilting angle between spindle axis and $\mathrm{Z}$ axis in vertical direction, which may induce the changing of the spindle tool orientation and hence affect the surface precision of machined parts. According to the study of Altintas et al. [1], the lead and tilt angles of the spindle tool determine the orientation of cutting tool and the engagement 
region, and thus affect the mechanics and dynamics of the process. Lim et al. [2] experimentally investigated the effects of tool orientation and cutting directions in 5-axis milling of a turbine blade. In this study, the cutting conditions with tool orientation in a horizontal inward direction with a tilt angle were verified as the best cutting strategy for machining turbine blades.

Basically, in five axis machining, the dynamic characteristic of the spindle tool may vary frequently with the changing configuration, which may lead to the change of tool point frequency response functions under excitations of cutting forces. Such a tool orientation was found to have considerable effect on the stability of processes [3-6]. In the studies of Ozturk et al., [5, 6], it was found that the tool orientation defined by lead and tilt angles greatly affect the dynamics of 5-axis ball-end milling, including the chatter behavior and stability limits. This was ascribed to the fact that tool orientation changed the directional coefficient matrix and the oriented transfer function matrix with the machine tool configuration. Hung et al. [7] investigated the influence of the spindle orientation on tool point dynamics and machining stability for a milling machine with rotary head and showed that the changing of the spindle tooling axis orientation indeed alter the structural configuration of the spindle tooling system and hence the machining performance. The limited cutting depth apparently reduced with the increasing orientation angle of spindle tool from the vertical position to horizontal positions. Law et al. [8] proposed a dynamic sub-structuring modeling method to investigate the orientationdependent dynamic behavior of machine tools with bi-rotary milling heads. Their results showed the tool point dynamics and stability varied with tool orientation by as much as $100 \%$ in dynamic stiffness and limiting stable cutting depth for changing orientation and swivel motion. Zhang et al. [9] also proposed an effective approach to predict the tool point frequency response function (FRF) based on the receptance coupling substructure analysis (RCSA). Using this approach, they found that the swivel angel of spindle tool has a greater influence on the variation of frequency and dynamic stiffness of dominant mode as compared to the change of rotational angle. In addition, $\mathrm{Du}$ et al. [10] presented a multi-rigid-body dynamic model to modeling the bi-rotary milling head at different swing state. In this approach, the structure components, including the rotary shaft, swivel shaft and housing were considered as rigid bodies and the bearings and flexible joints are modeled as elastic spring. The study results show the advantages in rapid evaluation of the influence of machining postures on the dynamics of the bi-rotary milling head. Recently, Du et al. [11] further proposed an integrated model by coupling the spindle-bearing module with the rotary-tilting spindle head structure. This model was employed to predict the tool point frequency response functions of the spindle tool at arbitrary posture. Essentially, the above-mentioned studies clearly indicate a strong dependence of machining stability on the spindle orientation.

This study was aimed at developing the swivel spindle head module composed of a rotary mechanism with direct driven motors and motorized spindle tooling system. In order to evaluate the machining stability at design phase, the dynamic characteristics and frequency responses of the rotary milling were analyzed with a finite element method, in which a full FE model of rotary milling head with spindle bearing module was created. With this model, the variations of the dynamic characteristics of the spindle tool with the changing of the titling configuration were examined. The proposed model and results can be applied in modeling a five-axis milling gantry machine with bi-rotary milling head for evaluation of the machining performance.

\section{CONFIGURATION OF A/C BI-ROTARY HEAD}

Figure 1 is the $\mathrm{A} / \mathrm{C}$ rotary milling head designed in this study, which is composed of three main parts, the rotary axis (C axis), swivel axis (A axis) and a motorized built-in high speed spindle. The $\mathrm{A}$ and $\mathrm{C}$ axis are driven by direct motors, respectively. The A axis can bring the spindle to swivel at the angle of \pm 100 degree. The $C$ axis is normally installed in the ram housing of a gantry milling machine and can drive the whole rotary head to rotate about vertical axis for full circle of \pm 360 degree. The maximum torque of the two axis is rated by 456 and $240 \mathrm{~N}-\mathrm{m}$, respectively, with speed of $340 \mathrm{rpm}$. The rotary axis (C axis) is supported by cross roller bearings with rigidity of 3500 and $4500 \mathrm{~N} / \mu \mathrm{m}$. in axial and radial directions. The swivel axis (A axis) is supported by angular contact bearings in DB configuration, which forces the roller bearing with radial and 

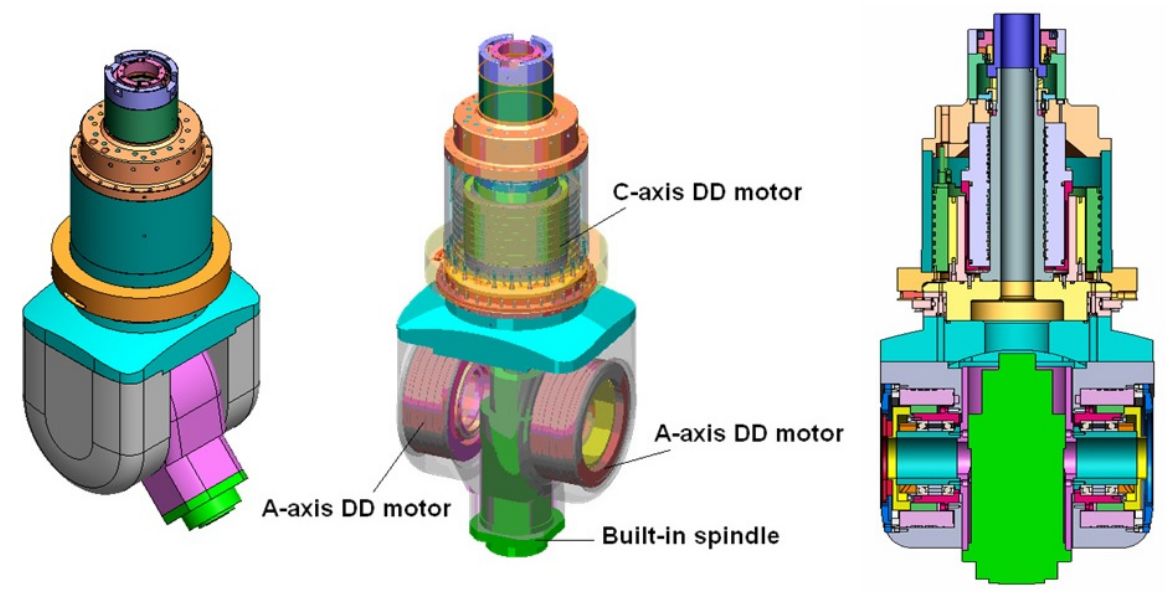

Figure 1. Configuration of the A/C bi-rotary milling head

axial rigidity of $450 \mathrm{~N} / \mu \mathrm{m}$ and $270 \mathrm{~N} / \mu \mathrm{m}$. The built-in spindle has a power of $21 \mathrm{~kW}$, maximum speed of $20000 \mathrm{rpm}$ and torque of $100 \mathrm{Nm}$. The front and rear bearings in spindle are $45 \mathrm{BNR} 10 \mathrm{H}$ and $30 \mathrm{BNR} 10 \mathrm{H}$ with radial and axial rigidity of $347 \mathrm{~N} / \mu \mathrm{m}$ and $77 \mathrm{~N} / \mu \mathrm{m}$, respectively.

\section{FINITE ELEMENT MODELING}

The finite element method was employed to analyze the vibration behavior of the rotary milling head. Figure 2 shows the simplified simulation model, in which the rotary axis was modeled as a hollow cylinder with equivalent weight of the real structure because of symmetry of the $\mathrm{C}$ axis about $\mathrm{Z}$ axis. The overall structure of the swivel module was maintained for analysis and the spindle unit was positioned at swinging angle of $0^{\circ}$ (vertical direction), $30^{\circ}, 45^{\circ}, 60^{\circ}$ and $90^{\circ}$ (horizontal direction), respectively. For clarification of the orientations of the system, we define a local coordinates system on the spindle unit, in which the $x$-axis is directed along the swinging motion, the $z$-axis is directed along the tool axis, and the $y$-axis is the lateral direction of the spindle tool axis, perpendicular to the $x$ and $z$ axis.

The finite element model of rotary milling head is shown in Figure 3. Each structural component of the system was meshed using eight-node hexahedron and ten-node tetrahedral element, with 64489 elements and 191273 nodes. The rolling bearings in the feeding mechanism of swivel axis and the spindle tool were included in the FE model. Following the method proposed in our previous study [12], for ball bearings, the rolling interfaces between rolling balls and raceways were simulated as surface-surface contact elements. The contact stiffness of the each bearing in spindle unit and swivel axis was estimated according the rated rigidity by manufactures.

Besides, since the influence of the swinging position of the spindle tool was mainly concerned in this study, the rotation of the rotary head about $\mathrm{Z}$ axis was fully constrained. The materials used for structural components, such as the housing of
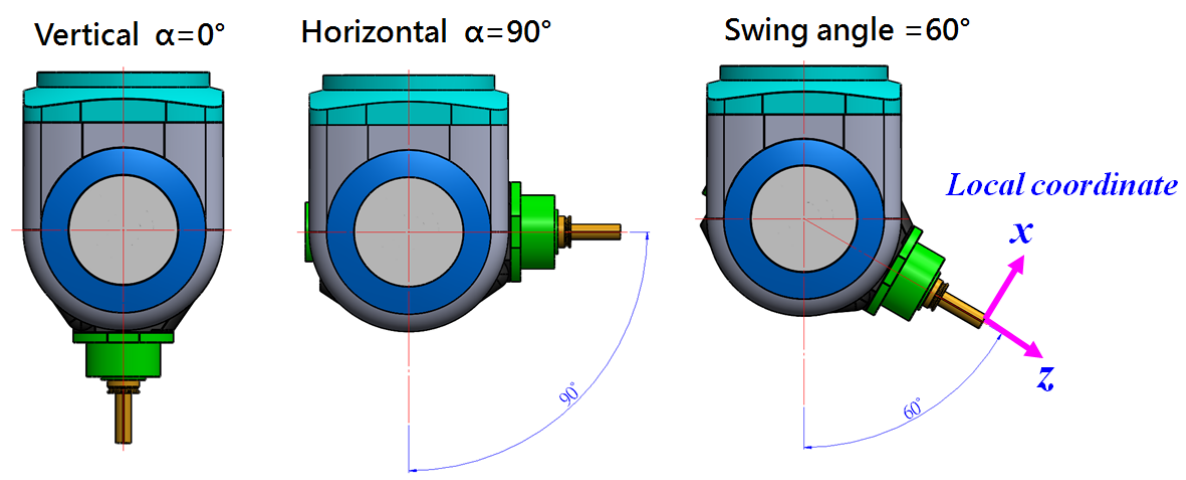

Figure 2. Coordinates system of rotary milling head 

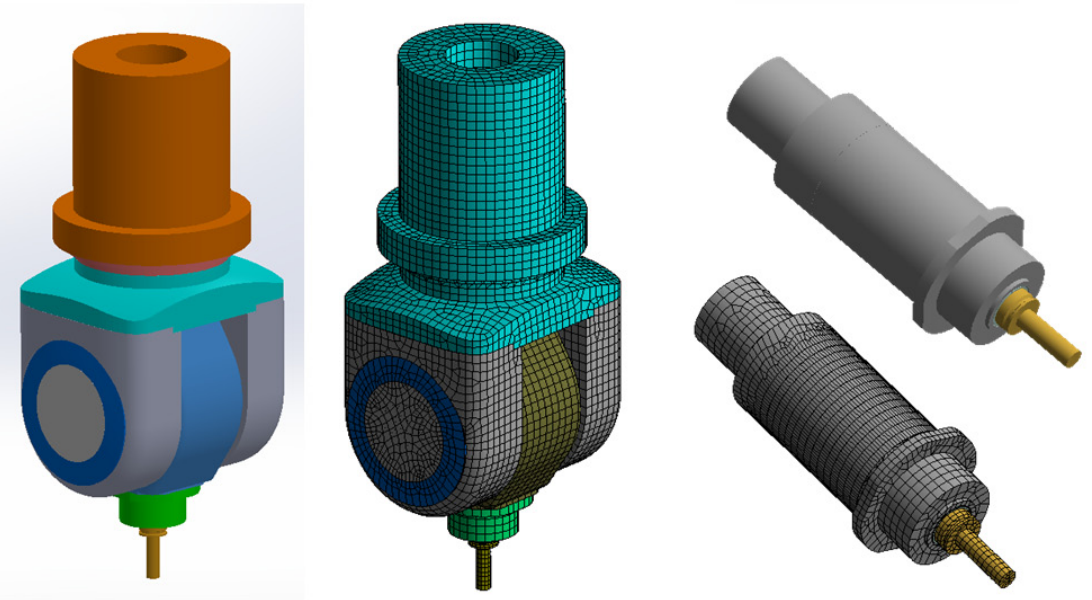

Figure 3. Solid model and finite element model of rotary milling head

swivel module, are made of gray cast iron with an elastic modulus $\mathrm{E}=660 \mathrm{GPa}$, Poisson's ratio $\mathrm{m}=0.3$, and density $\mathrm{r}=7200 \mathrm{Kg} / \mathrm{m}^{3}$. The materials of rolling components have an elastic modulus $\mathrm{E}=210 \mathrm{GPa}$, Poisson's ratio $\mathrm{m}=0.3$, and density $r=7800 \mathrm{Kg} / \mathrm{m}^{3}$. Besides, the interfaces of the tool bar/tool holder/spindle were assumed under elastic bonded conditions with appropriate contact stiffness.

With this model, the variations of the dynamic stiffness of the swivel spindle unit at different swing angles were evaluated through the harmonic analysis. The harmonic analysis was performed to measure the frequency response at the spindle unit. In the finite element governing equation for harmonic analysis, the damping matrix was assumed to be proportional to the structural stiffness matrix $[\mathrm{K}]$ according to the relationship $[\mathrm{C}]=\beta[\mathrm{K}]$. The value $\beta$ represents the structural damping constant, depending on the damping properties of the material. Here, the damping constant was assumed as 0.025 for the model.

\section{DYNAMIC CHARACTERISTICS ANALYSIS}

\section{Fundamental vibration modes}

Figure 4 shows the fundamental vibration modes of the rotary milling head positioned at the swinging angle of 45 degree. Essentially, the modal motions below $600 \mathrm{~Hz}$ are associated with the vibrations of the structure module, including the swivel mechanism and spindle housing. For example, the first mode at $291 \mathrm{HZ}$ is the forward and backward vibration motion of the spindle housing in the swivel direction about the pivot axis. The third mode at $589 \mathrm{~Hz}$ is the twisting vibration of the structure module of B-axis. The high frequency modes around 1000 and $1500 \mathrm{~Hz}$ are associated with the bending vibration of the spindle shaft. Especially the spindle tool shows a great vibration at the frequency of $1060 \mathrm{~Hz}$.

For the spindle tool positioned at the horizontal state and at the different angles, the vibration modes and frequencies are similar to those

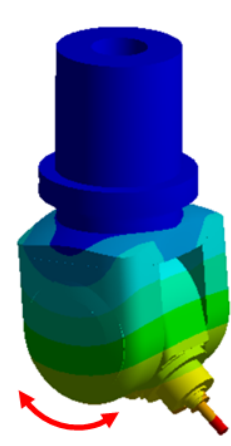

Mode $1291 \mathrm{~Hz}$
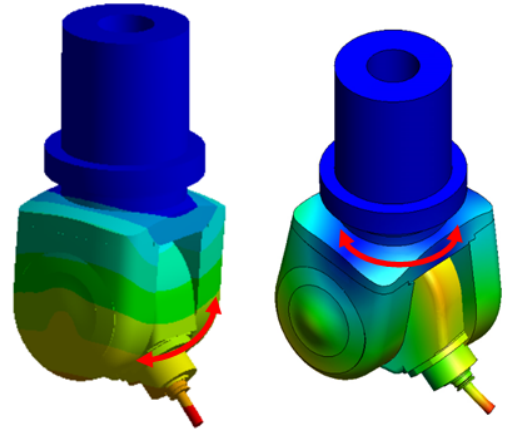

Mode $2 \quad 295 \mathrm{~Hz} \quad$ Mode $3 \quad 589 \mathrm{~Hz}$

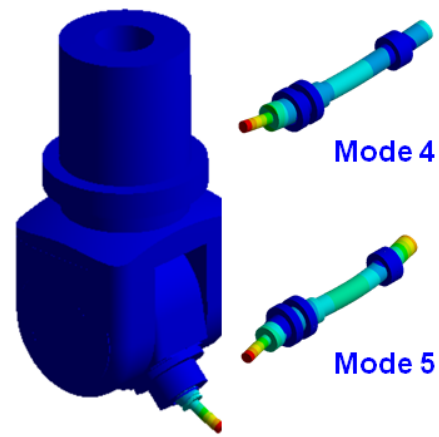

Mode $4 \quad 1060 \mathrm{~Hz}$

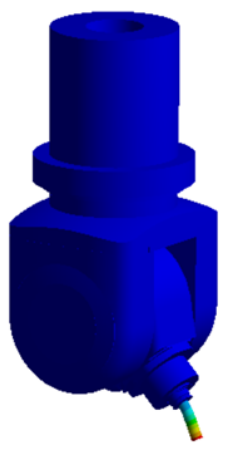

Mode $5 \quad 1500 \mathrm{~Hz}$

Figure 4. Fundamental vibration modes of rotary milling head 
observed at the swinging angle of 45 degree, as listed in Table 1. The lower and higher frequency modes are slightly different due to change of the configuration of the swinging spindle unit.

\section{Frequency response functions at tool tip}

In this analysis, a unit force was applied at the end of the spindle tool in the direction of $x$ and $y$ axes, respectively. The $x$-axis force is acted perpendicularly on the spindle tool along the swinging direction and the $y$-axis force is applied in lateral direction of the spindle axis. The frequency response functions measured at tool end were assessed from harmonic analysis, as follows.

Figure 5 (a) and (b) show the frequency response functions in $x$ and $y$ directions, which are expressed in terms of the compliance of spindle tool as functions of excitation frequency. It is noted that the spindle tool shows almost the same dynamic behavior to the excitation at tool end when it was positioned at a different swinging angle. As can be seen, the frequency responses below 800 $\mathrm{Hz}$ are mainly dominated by the structure vibration modes of the rotary head, in which the significant peak in $x$ direction occurring at $291 \mathrm{~Hz}$ is induced by the forward and backward vibration of the spindle housing along swinging direction, and the peak in $y$ direction at $295 \mathrm{~Hz}$ is induced by the lateral bending motion of the whole rotary module along $y$ axis. The compliance of the rotary milling head in lateral directions ( $y$-axis) ranges from 0.0306 to $0.0532 \mathrm{um} / \mathrm{N}$ and the compliance in swinging directions ( $x$-axis) is about 0.0306 to $0.075 \mathrm{um} / \mathrm{N}$, which vary with the positioned angle of the rotary milling head. It is obvious that the structure rigidity of the milling head in the swinging direction is higher than in the lateral direction (y-axis).

On the other hand, the swinging spindle tool shows significant dynamic responses at high fre- quency modes above $1000 \mathrm{~Hz}$. As it was found, the maximum compliances of the spindle tool in $x$ - and $y$-axis occur at the frequencies in the range of 1600 and $1800 \mathrm{~Hz}$, varying with the swinging of the spindle tool module. This mode with peak amplitude is associated with the natural frequency of the spindle and dominated by bending vibration of the spindle shaft. In addition, the maximum compliances of the spindle tool in $x$ and $y$ directions are affected to change with the swinging of the swivel spindle head, which are predicted to fall within the ranges from 0.309 to $0.50 \mathrm{um} / \mathrm{N}$ in $x$ direction and 0.342 to 0.374 $\mathrm{um} / \mathrm{N}$ in y direction, respectively. It is noted that when the spindle tool is positioned at the swinging angle of 45 degree, it demonstrates the most compliant behaviors, with maximum compliance of $0.5 \mathrm{um} / \mathrm{N}$ and $0.3774 \mathrm{um} / \mathrm{N}$ in $x$ and $y$ direction, as indicated in Table 2. The lowest value of the maximum compliance occurs at the horizontal position, with value of $0.304 \mathrm{um} / \mathrm{N}$ in $x$ direction and $0.341 \mathrm{um} / \mathrm{N}$ in $y$ direction, respectively.

\section{Variations of machining stability}

In order to evaluate the machining performance of the milling head at design stage, the machining stability was calculated based on the frequency response functions predicted at tool tip. The machining stability of the milling machine was predicted using the analytical model developed in the study [13]. The relationship between the chatter-free axial cutting depths $\left(Z_{\text {min }}\right)$ and the spindle speed $(n)$ in end-mill operation is stated as follows.

The speed-dependent transfer function $H(j w)$ representing the ratio of the Fourier transform of the displacement at the tool tip over the dynamic cutting force can be expressed as $H(j w)=R_{e}(w)+j I_{m}(w)$, where $R_{e}$ and $I_{m}$ are, respectively, the real and imaginary parts of the transfer

Table 1. Natural frequencies of milling head with change of swinging angle

\begin{tabular}{|c|c|c|c|c|c|}
\hline \multicolumn{7}{|c|}{ Vibration frequencies } \\
\hline Swinging angle & Mode 1 & Mode 2 & Mode 3 & Mode 4 & Mode 5 \\
\hline $0^{\circ}$ & 289 & 293 & 608 & 1060 & 1513 \\
\hline $30^{\circ}$ & 290 & 293 & 597 & 1064 & 1064 \\
\hline $45^{\circ}$ & 291 & 295 & 589 & 1060 & 1500 \\
\hline $60^{\circ}$ & 294 & 294 & 585 & 1061 & 1517 \\
\hline$* 90^{\circ}$ & 299 & 303 & 583 & 1059 & 1510 \\
\hline
\end{tabular}

* spindle tool at vertical direction ** spindle tool at horizontal direction 
a)

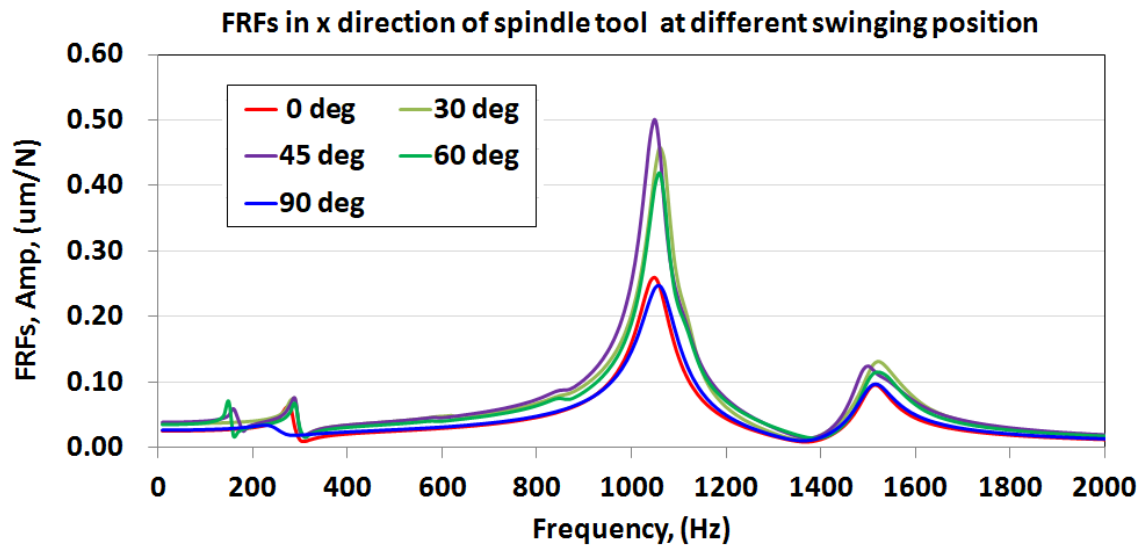

FRFs in $\mathrm{x}$ direction of spindle tool at different swinging position

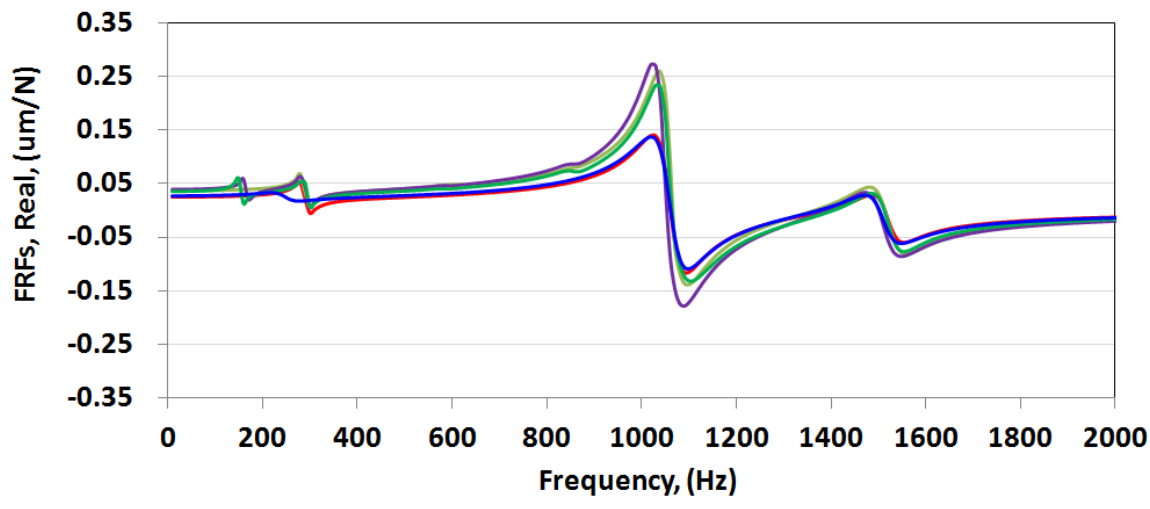

b)

FRFs in y direction of spindle tool at different swinging position
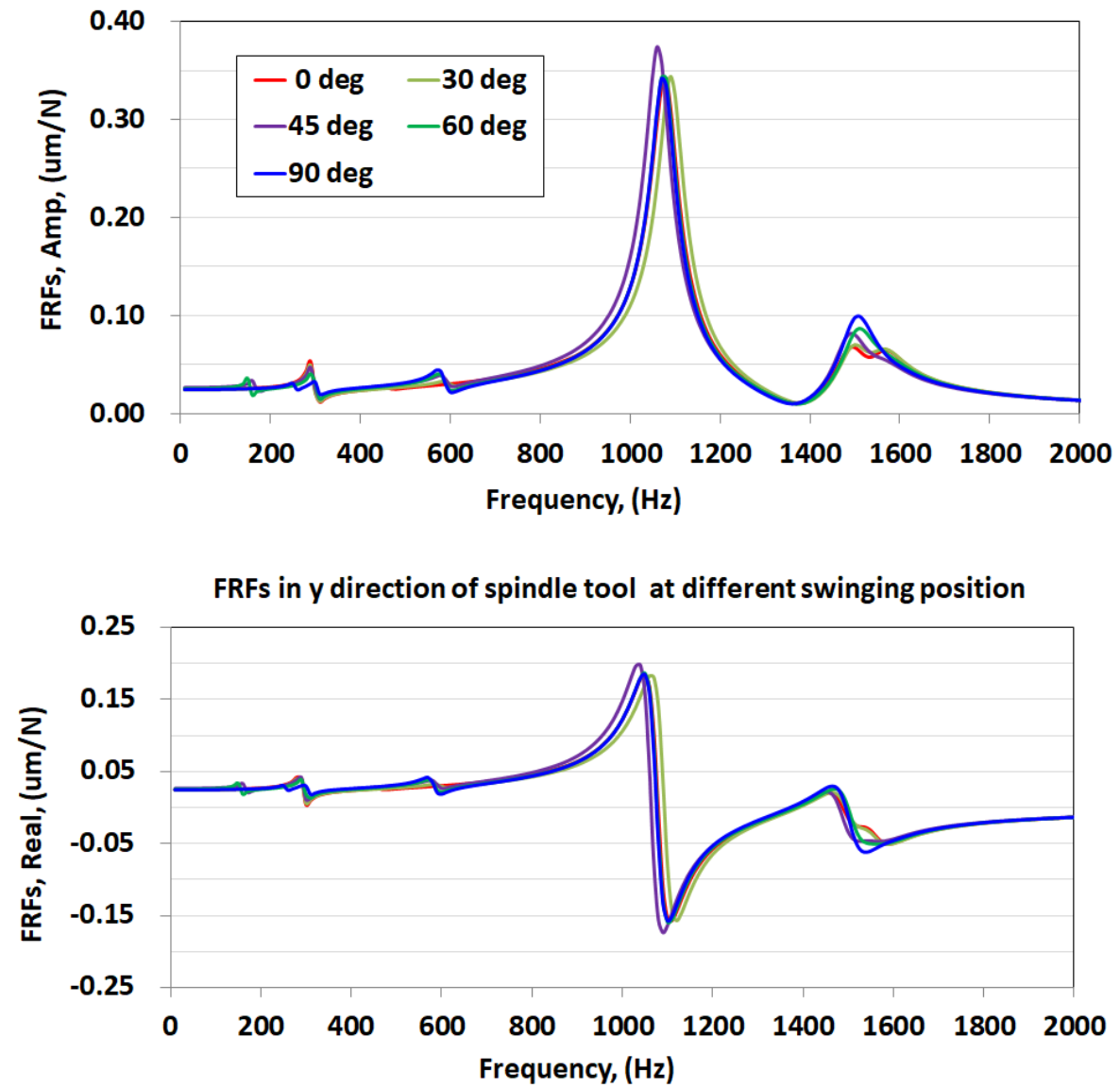

Figure 5. Frequency response functions of spindle tool of rotary milling head 


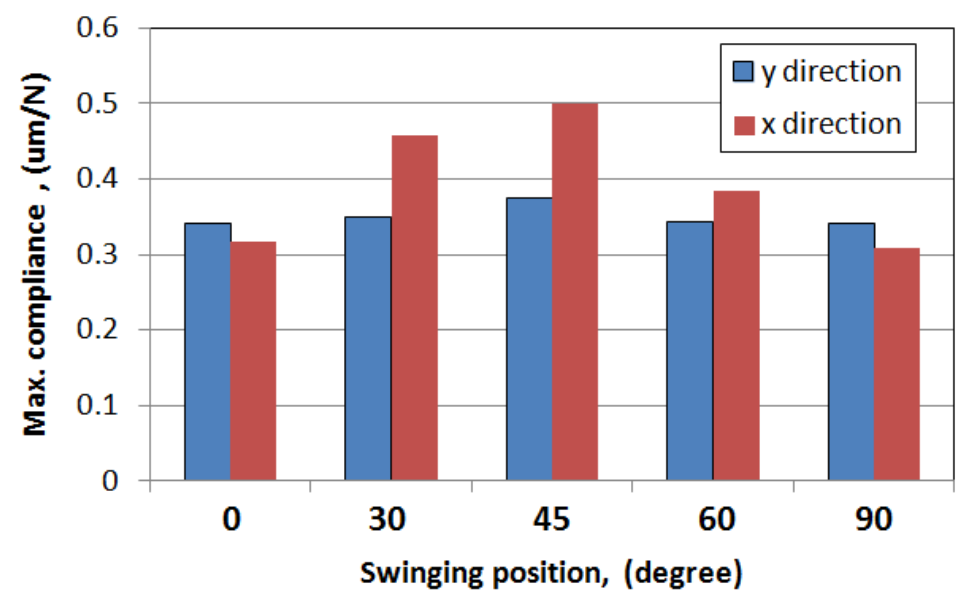

Figure 6. Comparisons of the compliances of rotary milling spindle tool at different swinging positions

function of the spindle tool tip. The limit cutting depth $Z_{\min }$ for stable machining at spindle speed $n$ is defined as:

$$
Z_{\text {min }}=\frac{-2 \pi R_{e}}{N K_{t}}\left(1+\frac{I_{m}}{R_{e}}\right)^{2}
$$

$n=\frac{60 \omega_{c}}{N(2 k \pi+\varphi)}$

$\varphi=\pi-2 \tan ^{-1}\left(I_{m} / R_{e}\right) \quad k=\operatorname{lobes}(0,1,2 \ldots)$

In the equation above, $K_{t}$ is the cutting resistance coefficients in the tangential direction to the cutter. $N$ is the number of cutter teeth and $k$ is the lobe number.

In this analysis, a two-tooth carbide cutter and the stock material of A17075 alloys were assumed for the calculation of the machining stability. The cutting resistance coefficients were calibrated as $\mathrm{K}_{\mathrm{t}}=800 \mathrm{~N} / \mathrm{mm}^{2}$ for Al6060T6 alloys [14].

The predicted stability lobes diagrams based of the vibration mode at frequency of $1060 \mathrm{~Hz}$ of spindle tool are illustrated in Figure 7(a) and 6(b) respectively, which clearly show the difference of the machining lobes in $x$ and $y$ directions. Besides, as observed in the figures, the cutting depths for stable machining change with the feeding directions and swinging of the A axis of spindle tool, as shown in Figure 8. Under the assumption of the milling cutter and part material used for stability analysis, the limited cutting depth in $x$-direction for high speed stable machining varies from 10.28 to $16.9 \mathrm{~mm}$. The limited cutting depth in $y$-direction is between 10.57 and $11.8 \mathrm{~mm}$. Essentially, the minimum limited cutting depth is about $10 \mathrm{~mm}$, occurring at the swinging angle of 45 degree, but the limited depth increases to a higher value when the A axis of spindle tool swings to the vertical or horizontal and other positions. The variations of the cutting depth within the swinging angles range from $11 \%$ to $40 \%$, depending on the feeding direction in $y$ and $x$ directions. In addition, the changing stability observed in Figure 8 also indicates the weakest point of the machining process. This means the stable machining depth of the rotary milling tool will be confined within the value of $10 \mathrm{~mm}$ at the tool orientation of 45 degree, yielding a lower material remove rate due to this limitation in selecting the machining conditions.

Overall, current results clearly show that the feeding direction and swinging positions of rotary milling head have a significant influence on the dynamic characteristics and machining ability of the spindle tool. Realization of such characteristics from this study can help an engineer to propose improvement strategies for the design of a five axis milling machine with the desired dynamic performance. The results of this study can also provide a reference for appropriate cutting conditions for achieving the required machining performance.

\section{CONCLUSIONS}

This study investigated the variation of the dynamic characteristics and machining stability of rotary milling tool. On the basis of the results, the following conclusions were drawn:

1. A full finite element model of rotary milling head with spindle tool is required for accurately describing the dynamic characteristics of the milling tool system, which include the lower frequency vibration modes of the whole rotary 
a)

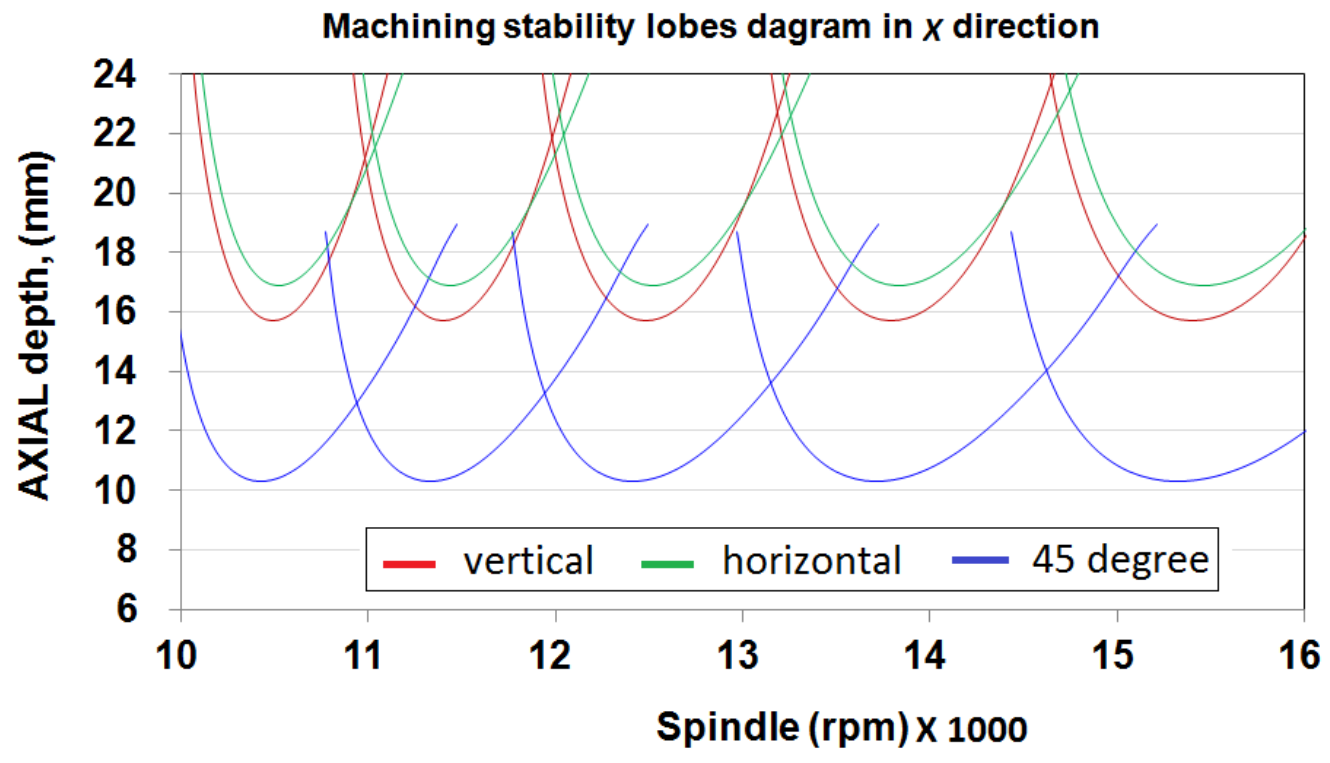

b)

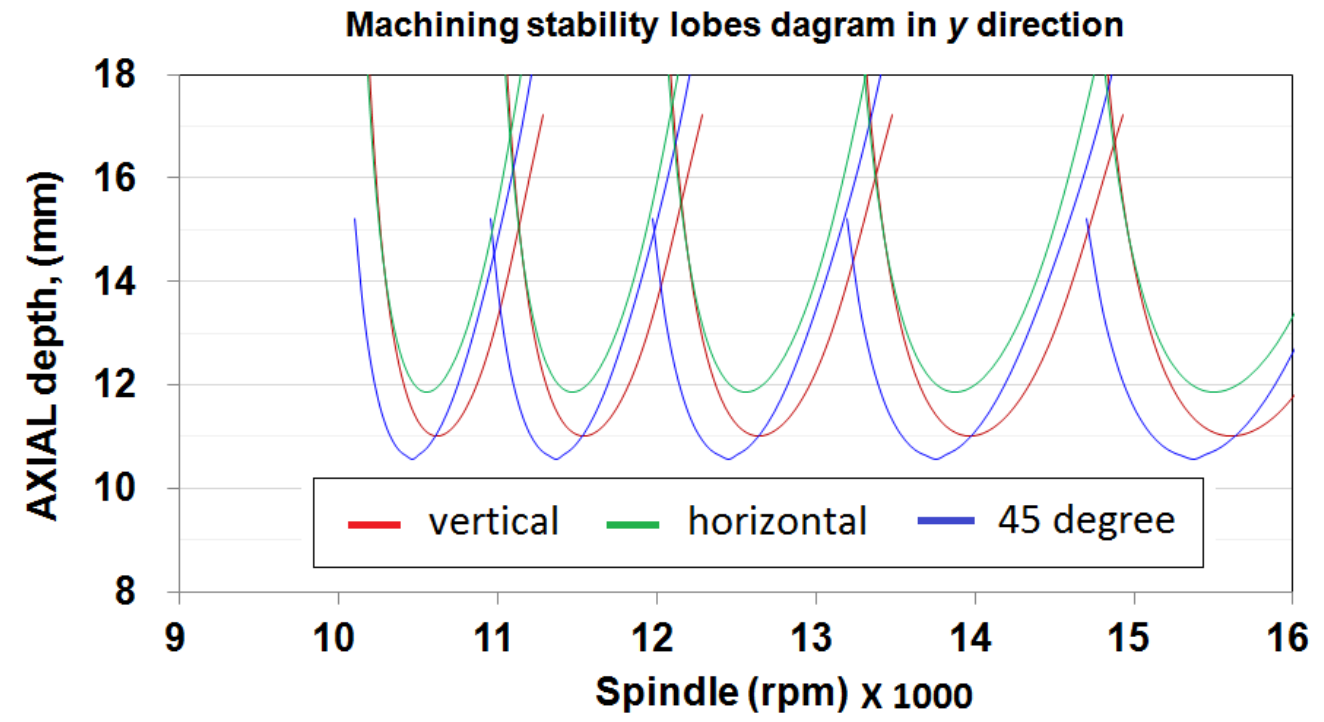

Figure 7. Machining stability lobes diagram of the spindle tool under different swinging position

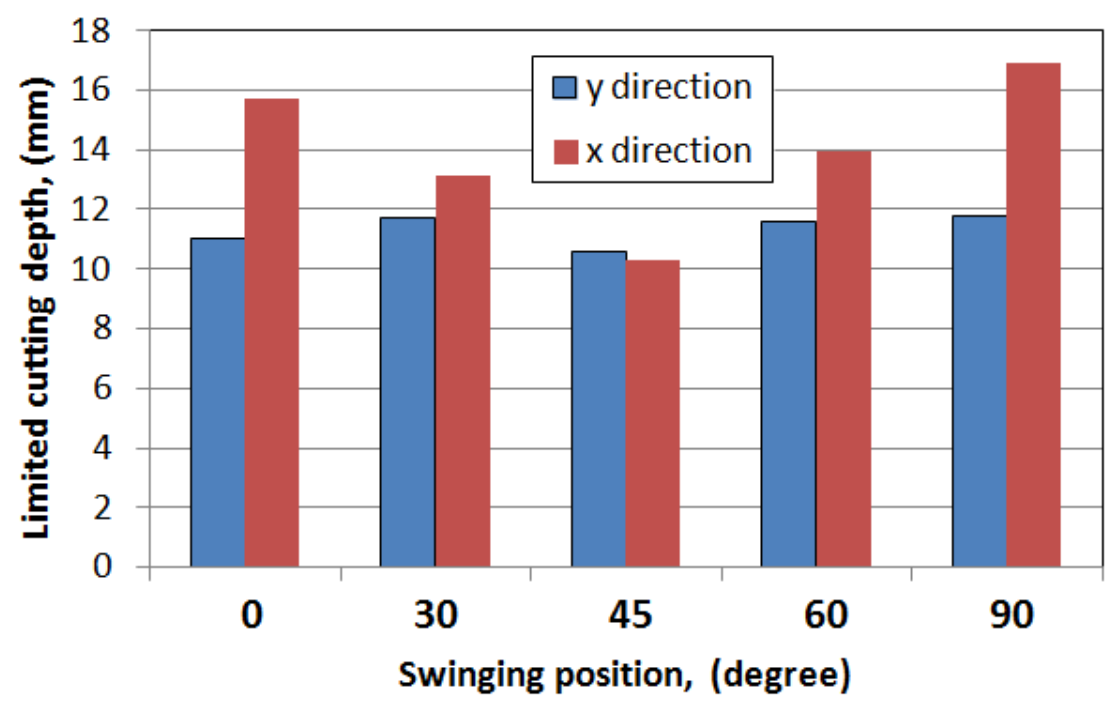

Figure 8. Comparisons of the limited cutting depth of spindle tool under different swinging position 
structure components and swivel axis, and high frequency modes of spindle bearing system.

2. The dynamic compliance associated with frequency response functions of spindle tool can be affected to vary with the changing of the swinging positions. It is noted that the spindle tool shows the most compliant behavior at the swinging angle of 45 degree direction. The lowest dynamic compliances occur at the vertical and horizontal positions.

3. The results of machining stability analysis clearly indicate that the feeding direction and swinging positions of rotary milling head have a significant influence on the dynamic characteristics and machining ability of the spindle tool. The variations of the cutting depth for stable machining fall in the range of $11 \%$ to $40 \%$, depending on the feeding direction and swinging angle of the swivel axis.

4. The finite element model and modeling methodology presented in this paper can be applied to develop a whole five axis milling system with bi-rotary milling head to achieve the desired dynamic characteristics and machining performance at design phase. The results of this study can also provide a reference for selection of the cutting conditions to achieve the required machining performance without chatter.

\section{Acknowledgements}

The authors gratefully acknowledge the supports of the National Science Council in Taiwan through project number MOST104-2622-E-167011-CC3 and POSA Precision Spindle Co., Ltd.

\section{REFERENCES}

1. Alintas, Y., Shamoto, E., Lee, P. and Budak, E. Analytical prediction of stability lobes in ballend milling. Transactions of the ASME Journal of Manufacturing Science and Engineering, 121(4), 1999, 586-592.

2. Lim, T.S., Lee, C.M., Kim, S.W. and Lee, D.W. Evaluation of cutter orientations in 5-axis high speed milling of turbine blade, Journal of Materials Processing Technology, 13-131, 2002, 401-406.

3. Ozturk, E., E. Ozlu, E. and Budak, E. Modeling dynamics and stability of 5-axis milling processes, in:
Proceedings of the10th CIRP Workshop on Modeling of Machining Operations, Calabria, Italy, 27-28 August, 2007, 469-476.

4. Budak, E., Ozturk, E. and Tunc, L. T. Modeling and simulation of 5-axis milling processes, CIRP Annals-Manufacturing Technology, 58(1), 2009, 347-350.

5. Ozturk, E. and Budak, E. Modeling of 5-axis milling processes, Machining Science and Technology 11 (3) , 2007, 287-311

6. Ozturk, E., Tunc, L.T. and Budak, E. Investigation of lead and tilt angle effects in 5-axis ball-end milling processes, International Journal of Machine Tools and Manufacture,49, 2009, 1053-1062.

7. Hung, J.P., Chen, Y.J. and Luo, T.L. Effect of tool orientation on the machining stability of a milling machine with swinging head, World Academy of Science, Engineering and Technology, 77, 2013, 958-964.

8. Law, M., Grossi, N., Scippa, A., Phani, A. and Altintas, Y. Modeling the orientation-dependent dynamics of machine tools with gimbal heads, Third International Chemnitz Manufacturing Colloquium (ICMC 2014), 2014, 1-16.4

9. Zhang, J., Li, J., Xie, Z., Du, C., Gui, L. and Zhao, W. Rapid dynamics prediction of tool point for birotary head five-axis machine tool. Precision Engineering, 48, 2017, 203-215.

10. Du, C., Zhang, J., Lu, D., Zhang, H. and Zhao, W. A parametric modeling method for the posedependent dynamics of bi-rotary milling head, Proceedings of the Institution of Mechanical Engineers, Part B: Journal of Engineering Manufacture, 232(5), 2016, 797-815.

11. Du, C., Zhang, J., Lu, D., Zhang, H. and Zhao, W. Coupled model of rotary-tilting spindle head for pose-dependent prediction of dynamics, Journal of Manufacturing Science and Engineering, 140(8), 2018, 081008.

12. Hung, J.P., Lai, Y.L., Luo, T.L. and Su, H.C. Analysis of the machining stability of a milling machine considering the effect of machine frame structure and spindle bearings: experimental and finite element approaches, The International Journal of Advanced Manufacturing Technology, 68(9-12), 2013, 2393-2405.

13. Altintas, Y. and Budak, E. Analytical prediction of stability lobes in milling. CIRP Annals-Manufacturing Technology, 44, 1995, 357-362.

14. Tsai, M.Y., Chang, S.Y., Hung, J.P. and Wang, C.C. Investigation of milling cutting forces and cutting coefficient for aluminum 6060-T6. Computers \& Electrical Engineering, 51, 2016, 320-330. 